\title{
Degradation of anti-inflammatory drug diclofenac in sewage water
}

\author{
Katarína Gazdováa ${ }^{a}$ Emília Kubiňákováa ${ }^{a}$ Ján Híveša , Tomáš Mackul’ak \\ ${ }^{a}$ Institute of Inorganic Chemistry, Technology and Materials, \\ Faculty of Chemical and Food Technology STU in Bratislava, \\ Radlinského 9, 81237 Bratislava, Slovak Republic \\ ${ }^{b}$ Institute of Chemical and Environmental Engineering, \\ Faculty of Chemical and Food Technology STU in Bratislava, \\ Radlinského 9, 81237 Bratislava, Slovak Republic \\ emilia.kubinakova@stuba.sk
}

\begin{abstract}
In recent years, interest in the presence of chemical and biological pollutants (drugs, pesticides, heavy metals etc.) in sewage water has been permanently increasing and, at the same time, significant effort to eliminate them has been shown. The aim of this work was to investigate the influence of ferrates activity on the decomposition of the drug diclofenac (DCF), which is commonly present in sewage water. The main task is to follow the effect of potassium ferrate dosage on DCF degradation and to evaluate the most effective ferrates concentration in solution. Subsequently, real samples of waste water containing a significant amount of various micro-pollutants were treated by the same amount of ferrates as laboratory samples. High-performance liquid chromatography (HPLC) was used for the sample analysis. Ferrates removal effectiveness was determined by comparing the chromatographic peak areas of residual DCF in the treated samples. Removal efficiency of diclofenac is proportional to the concentration of potassium ferrate in the treated solutions.
\end{abstract}

Keywords: potassium ferrate, diclofenac, sewage water

\section{Introduction}

Over the last two decades, pharmaceuticals have been receiving increasing attention as potential bioactive chemicals in the environment. The continuously ascending consumption of pharmaceuticals causes introduction of these drugs and their metabolites into the environment. Although concentrations of pharmaceuticals are prevalent at small amounts, they can affect water quality and potentially negative affect drinking water supplies, ecosystem and human health. Various studies have shown that treated municipal wastewater in Europe contributes significantly to water pollution by micro-pollutants (Loos et al., 2010; Verlicchi et al., 2012; Loos et al., 2013; Rivera-Utrilla et al., 2013; Luo et al., 2014). One of the pharmaceuticals, most (a)<smiles>O=C(Cc1ccccc1Nc1c(Cl)cccc1Cl)O[Na]</smiles>

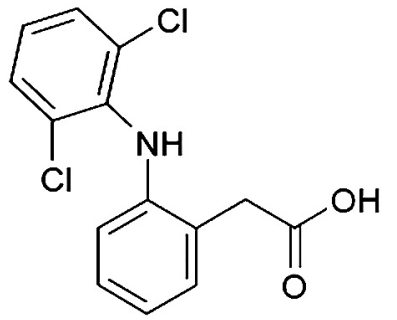

(b)
Fig. 1. Structural formula of diclofenac sodium (a) and diclofenac (b). frequently and at the highest concentration levels found, is diclofenac (Fig. 1).

Diclofenac (2 [(2,6-diclorophenyl) amino] phenyl acetate) is a nonsteroidal anti-inflammatory drug (NSAID) commonly used for the treatment of rheumatoid arthritis, osteoarthritis, musculoskeletal injuries and post-surgery analgesia in human and veterinary medicine. Due to its broad range of treatments, diclofenac is prepared in a wide range of formulations including tablets, capsules, drops, injection, suppositories, gel, and ointment. Only $60 \%$ of the drug reaches systemic circulation unchanged following oral administration. The principal metabolite in humans is 4'-hydroxydiclofenac; the amount of diclofenac excreted in urine accounts for 20 to $30 \%$ of the administered dose, and in bile for 10 to $20 \%$ (Todd and Sorkin, 1988; Evanson, 2007).

Usual wastewater treatment plants are ineffective in eliminating diclofenac, and most of the released substance passes through the treatment plants without any change. Various treatment advanced oxidation processes (AOPs) for the removal of DCF from sewage water have been tested; such as $\mathrm{UV} / \mathrm{H}_{2} \mathrm{O}_{2}$ and/or in combination with $\mathrm{O}_{3}$ (Vogna et al., 2004), sonolysis (US) and ozonization, and their combination (Naddeo et al., 2009), classic Fenton reaction (Manu and Mahanood, 2012) or photo Fenton oxidation (Pérez-Estrada et al., 2015), $\mathrm{TiO}_{2}$ photocatalysis (Calza et al., 2006; Rizzo et 
al., 2009), electro-oxidation at boron doped diamond - BDD (Zhao et al., 2009), or homogeneous and heterogeneous sonolysis (Güyera and Ince, 2011). Results of these studies showed that the best removal efficiencies were achieved by electro-oxidation at BDD and by Fenton reaction. Mineralization degree of diclofenac with the initial concentration of $30 \mathrm{mg} \mathrm{l}^{-1}$ using BDD reached $72 \%$ after a 4 hour treatment with the applied bias potential of $4.0 \mathrm{~V}$ (Zhao et al., 2009). Fenton oxidation of a similar initial DCF concentration achieved $74.25 \%$ of DCF reduction also within 4 hours (Manu and Mahanood, 2012). Slightly lower effectivities were observed using $\mathrm{UV} / \mathrm{H}_{2} \mathrm{O}_{2} / \mathrm{O}_{3}$ and $\mathrm{US} / \mathrm{O}_{3}$. Removal efficiencies of these treatment techniques were from $22 \%$ to $52 \%$ for application times of (40-90) minutes (Vogna et al., 2004, Naddeo et al., 2009).

Ferrate $\left(\mathrm{Fe}^{\mathrm{VI}} \mathrm{O}_{4}{ }^{2-}\right)$ belongs to a group of AOPs; $\mathrm{Fe}(\mathrm{VI})$ has drawn interest due to its properties such as oxidizing power, selective reactivity, relative stability in salt forms (compared with other high valent iron $\mathrm{Fe}(\mathrm{IV})$ and $\mathrm{Fe}(\mathrm{V})$ ), and non-toxic decomposition by-products of the ferric ion (Sharma et al., 2016; Alsheyab et al., 2009). In environmental remediation processes, Fe(VI) performs the functions as a green oxidant, disinfectant, coagulant, and antifoulant, and therefore it is a promising multi-purpose water treatment chemical (Manoli et al., 2017; Mackulak et al., 2016; Barışçı et al., 2016). In this paper, we focused on the influence of electrochemically synthesized potassium ferrate on the decomposition of the drug diclofenac, commonly present in sewage water. The effect of different concentrations of $\mathrm{Fe}(\mathrm{VI})$ on DCF degradation was evaluated.

\section{Experimental}

\section{Chemicals}

Potassium ferrate - electrochemically prepared with the final concentration of nearly $80 \%(\mathrm{w} / \mathrm{w})$ (Kubiňáková et al., 2015)

$\mathrm{C}_{14} \mathrm{H}_{10} \mathrm{Cl}_{2} \mathrm{NNaO}_{2}$ - diclofenac sodium (p.a.), purity at least $96.5 \%(\mathrm{w} / \mathrm{w})$, SIGMA-ALDRICH

\section{Analysis of sewage water by HPLC}

The measurements were carried out on a HPLC-PDA device detector (model Young Lin 9100). Mobile phase used for the analysis was methanol/water, the ratio of these two phases was gradually changed during the analysis from the initial value $\left(\varphi_{r}=1: 9\right)$ to the final value $\left(\varphi_{r}=9: 1\right)$ achieved in the 16 -th minute at the end of the analysis. The column used was a Grace Smart TM, RP-18, (Grace, USA) with the length of $150 \mathrm{~mm}$, inner diameter of $4.6 \mathrm{~mm}$

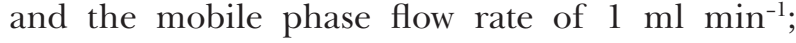
PDA detector wavelengths were: $222 \mathrm{~nm}, 254 \mathrm{~nm}$, $320 \mathrm{~nm}$, and $380 \mathrm{~nm}$.

\section{Results and discussion}

The stock solution of DCF with the concentration of $10.13 \mathrm{mg} \mathrm{l}^{-1}$ was prepared by dissolving an appropriate amount of the compound in distilled water and it was stored below the temperature of $5{ }^{\circ} \mathrm{C}$. Four different ferrates concentrations $(0.1,0.5,1,5) \mathrm{mg} \mathrm{l}^{-1}$ were considered for the investigation of the DCF degradation capability. Appropriate amounts of powder Fe(VI) were added to $100 \mathrm{ml}$ of the DCF solution; the samples were subsequently measured.

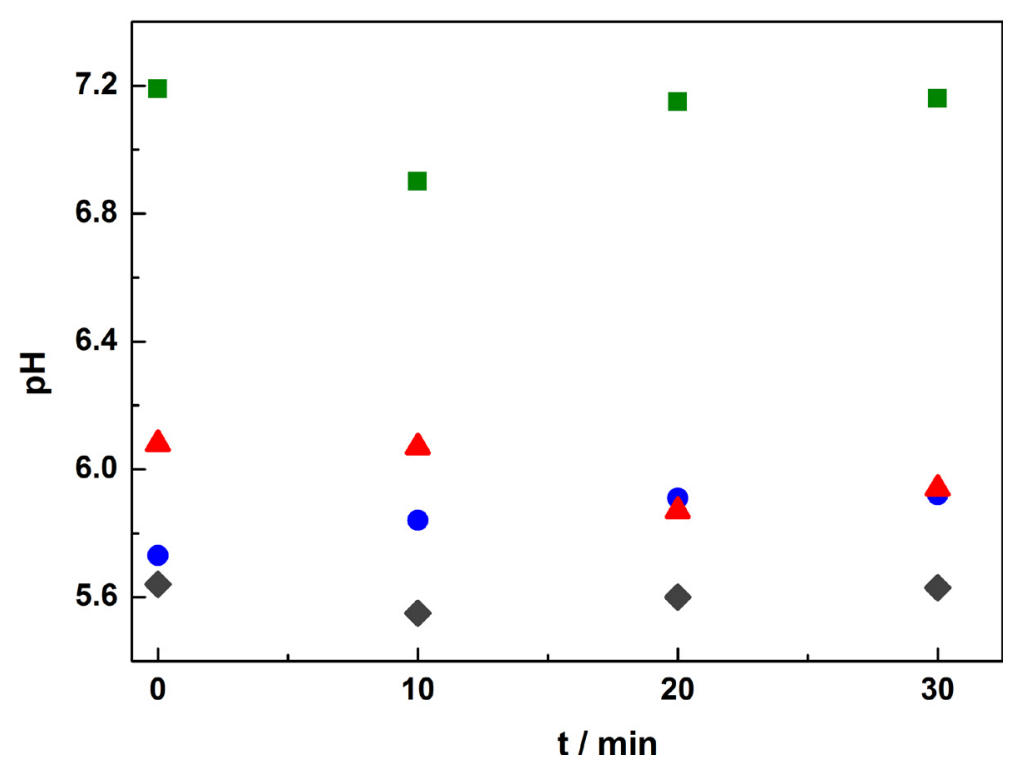

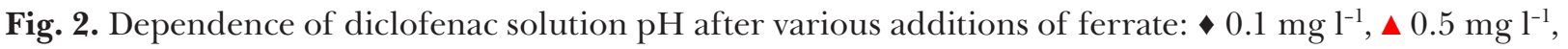
- $1 \mathrm{mg} \mathrm{l}^{-1}$, $5 \mathrm{mg} \mathrm{l}^{-1}$, on time; pH value of basic DCF solution was 5.6. 
Changes of $\mathrm{pH}$ were measured every 10 minutes during the first half hour until the ferrate reaction was complete (Fig. 2). pH was measured with a digital $\mathrm{pH}$ meter $\mathrm{pH}$ Testr 30 (Helago, Czech Republic).

Acidobasic properties of the solution did not vary significantly during the measurements. The $\mathrm{pH}$ values increased with the increasing dosage of ferrate added to the DCF solution. The highest $\mathrm{pH}$ values were reached for ferrates concentration of $5 \mathrm{mg} \mathrm{l}^{-1}$.

Samples were analyzed by the HPLC method after complete reaction of ferrate (non-violet color of the solution). Retention time was used as the qualitative variable for DCF estimation on the chromatograms. As the quantitative parameter, the size of undercurve-area (peak area) on the chromatogram was used. Degradation efficiency $(\eta)$ of ferrate on DCF was calculated according to Eq. 1,

$$
\eta=\frac{A_{0}-A_{i}}{A_{0}} \cdot 100 \%
$$

where $A_{0}$ is the initial under-curve-area of the stock solution and $A_{i}$ is the peak area of the remaining DCF in the measured sample.

A comparison of the individual chromatograms provided the definition of some trends in the structure of the DCF degradation product. Application of ferrate causes the formation of peaks on the chromatograms with lower retention times while the peak for DCF declines. In the following figures, two examples of chromatograms can be seen: for stock solution (Fig. 3) and for sample with the highest concentration of ferrates (Fig. 4). Chan-

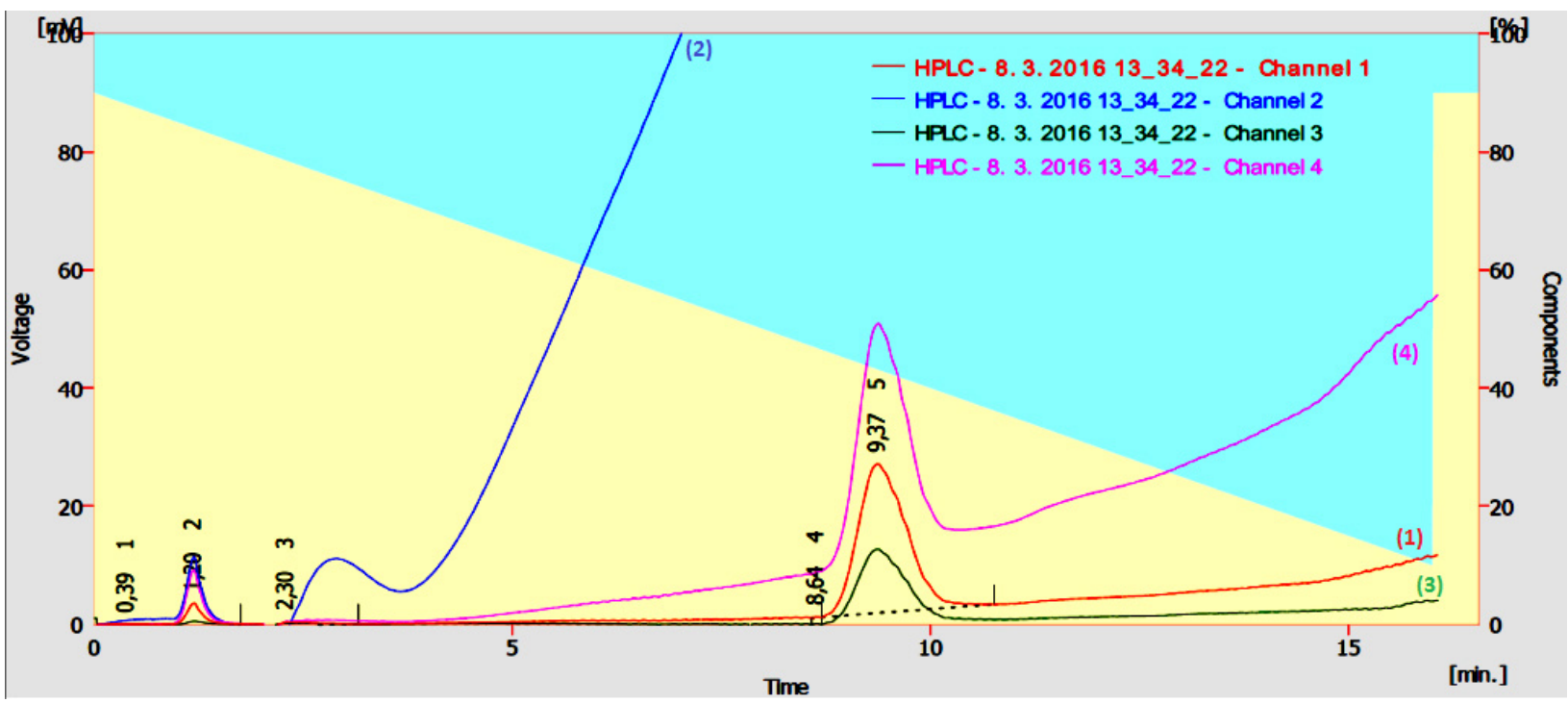

Fig. 3. Chromatograms of DCF stock solution $\left(10.13 \mathrm{mg} \mathrm{l}^{-1}\right)$.

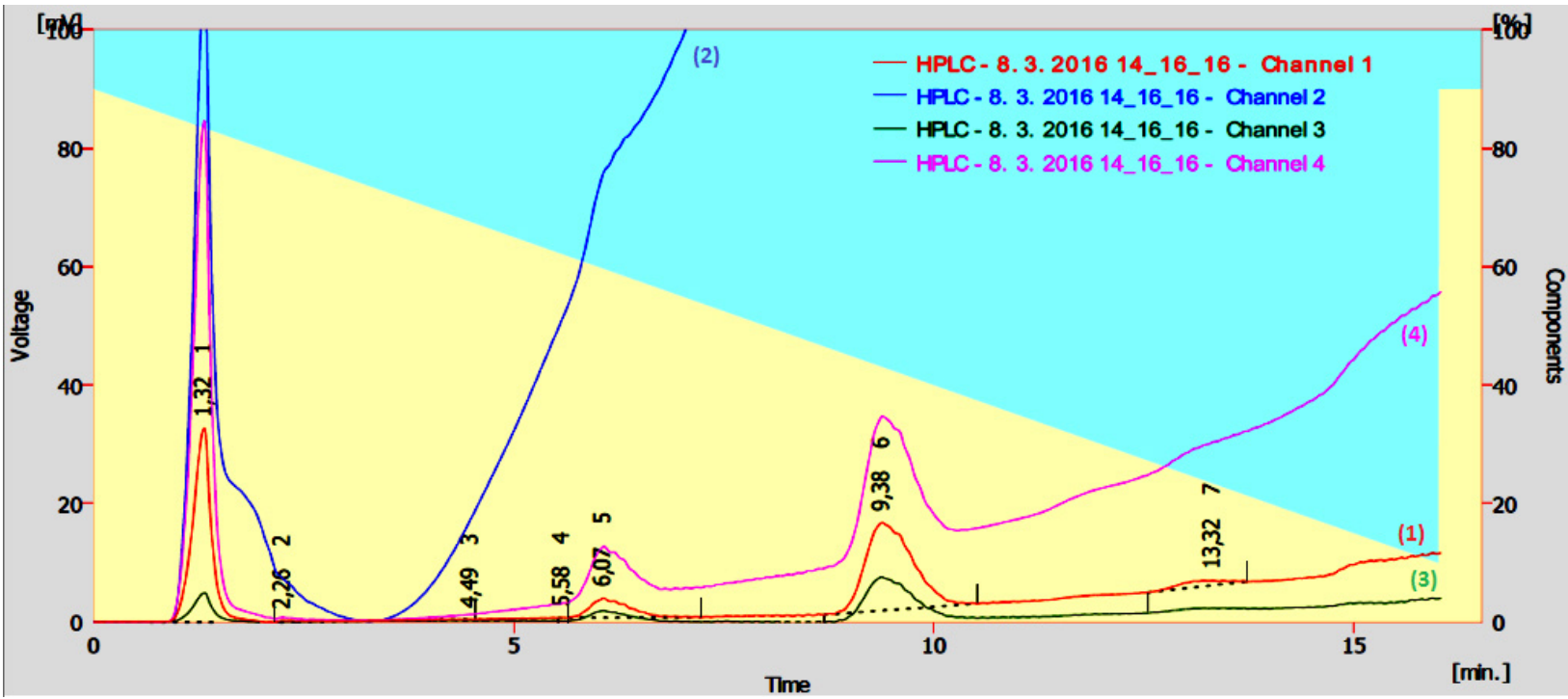

Fig. 4. Chromatograms of DCF solutions and degradation products for ferrate concentration of $5 \mathrm{mg} \mathrm{l}^{-1}$. 
nel lines represent specific wavelengths. Generally, data detected by Channel 4, which was the most sensible for DCF, were used. Chromatogram in Fig. 3 contains one dominant peak for DCF at the retention time of 9.37 minutes. Chromatogram in Fig. 4 shows a lower peak for DCF compared with that in Fig. 3. The dominant peak was observed at a lower retention time, 1.32 minutes. Amounts of the remaining DCF in the solutions decreased with the increasing ferrate dosage in all samples. Retention time of the detected compounds was reduced after the ferrate treatment; it follows from the simpler structure of the compounds. Samples with lower ferrates concentration $\left(0.1\right.$ and $\left.0.5 \mathrm{mg} \mathrm{l}^{-1}\right)$ have displayed many different peaks with a higher retention time, corresponding to compounds with more complicated structure than DCF, which shows that the original structure of DCF changed.

Values of the DCF peak area obtained from the HPLC analysis were evaluated and the results are summarized in Tab. 1. Extent of the degradation was more significant at the higher concentration of the ferrate solution. Efficiency of DCF removal is represented in Fig. 5.

The best results on DCF removal in the tested solutions were found for the ferrate concentration of
Tab. 1. Summarized results for the application of different ferrate concentrations to DCF; concentrations of added ferrates $c\left(\mathrm{Fe}^{\mathrm{VI}}\right)$, retention time for detected DCF peak $\left(t_{R}\right)$, $\mathrm{pH}$ values of solutions, removal efficiency $(\eta)$.

\begin{tabular}{cccc}
\hline$c\left(\mathrm{Fe}^{\mathrm{VI}}\right) / \mathrm{mg} \mathrm{l}^{-1}$ & $t_{R} / \min$ & $\mathrm{pH}$ & $\eta / \%$ \\
\hline 0.0 & 9.9 & 5.6 & - \\
0.1 & 9.9 & 5.6 & 4.2 \\
0.5 & 9.6 & 5.9 & 4.3 \\
1.0 & 9.4 & 5.9 & 7.8 \\
5.0 & 9.6 & 7.2 & 43.5 \\
\hline
\end{tabular}

$5 \mathrm{mg} \mathrm{l}^{-1}$, which was chosen for the application in real wastewater samples. Samples of savage water were from the Petržalka wastewater treatment plant (WWTP), from influent (Tab. 2).

The efficiency in an influent water sample (14.5\%) was significantly lower compared with the same ferrate concentration in laboratory samples $(43.5 \%)$. This can be caused by the presence of many other micro-pollutants in the real wastewater sample. Compounds with a simpler structure (without or

Tab. 2. Summarized results for the application of ferrate to DCF in WWTP of Petržalka; concentrations of added DCF, concentrations of present DCF, concentration of ferrate $c\left(\mathrm{Fe}^{\mathrm{VI}}\right)$, retention time $\left(t_{R}\right)$, peak area $\left(A_{i}\right)$, removal efficiency $(\eta)$.

\begin{tabular}{ccccccc}
\hline \multirow{2}{*}{$\begin{array}{c}c \text { (added DCF }) \\
\mathrm{mg} \mathrm{l}^{-1}\end{array}$} & $c$ (presentedDCF $)$ & $c\left(\mathrm{Fe}^{\mathrm{VI}}\right)$ & $t_{R}$ & $A_{i}$ & $\eta$ \\
& $\mu \mathrm{g} \mathrm{l}^{-1}$ & $\mathrm{mg} \mathrm{l}^{-1}$ & $\min$ & $\mathrm{mV} \mathrm{s}$ & $\%$ \\
\hline \multirow{2}{*}{ influent } & \multirow{2}{*}{10} & 2.3 & - & 9.22 & 1444.4 & - \\
& & & 5 & 9.32 & 1234.9 & 14.5 \\
\hline
\end{tabular}

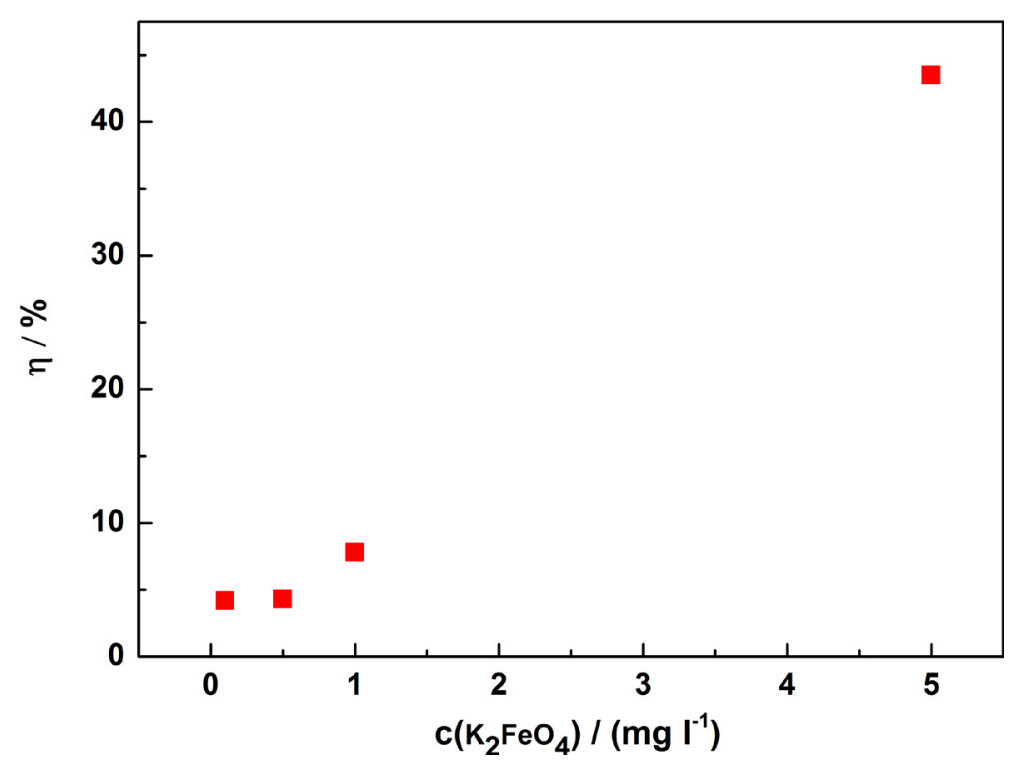

Fig. 5. Dependence of the DCF removal efficiency at the potassium ferrate concentrations of $(0.1,0.5,1,5) \mathrm{mg} \mathrm{l}^{-1}$. 
with only one benzene ring) than DCF are attacked by ferrate preferentially.

Overall comparison of the DCF removal efficiency of various advanced oxidation processes proved that oxidation of ferrate is rather complicated. Different concentrations of DCF were studied at various conditions and applications times. Some trends in the structure of the DCF degradation product have been suggested in several papers. More than 20 intermediates in several tentative degradation routes were presented (Pérez-Estrada et al., 2015; Zhao et al., 2009). The main intermediates, including 2,6-dichlorobenzenamine, 2,5-dihydroxybenzyl alcohol, and benzoic acid, were identified. These intermediates participate in further multistep degradation involving hydroxylation, decarboxylation, and oxidation reactions. Final products of some of these reactions were small molecular acids and compounds.

\section{Conclusion}

Efficiency of the potassium ferrate oxidation process on the degradation of diclofenac in aqueous solutions was investigated. Dependence of DCF solutions $\mathrm{pH}$ on the different size of ferrate additions vs. time was investigated. Weak acidic environment for all samples and for all additions of $\mathrm{Fe}(\mathrm{VI})$ provided the ferrates with sufficient oxidation power. Removal efficiency of DCF in the solution increased with the increasing ferrate concentration. Addition of ferrate to sewage water from the Petržalka WWTP achieved significantly lower removal efficiency of DCF, which can be caused by the presence other micro-pollutants in water, their preferential reactions with ferrate(VI), and also their subsequent reactions with DCF. Research focused on the toxicity assessment of degradation products and by-products of DCF, and consequent confirmation of general toxicity are required.

\section{Acknowledgement}

This work was supported by the Ministry of Education, Science, Research and Sport of the Slovak Republic within the project VEGA 1/0543/15.

\section{References}

Alsheyab M, Jiang JQ, Stanford C (2009) J. Environ. Manage. 90: 1350-1356.

Barışçı S, Särkkä H, Sillanpää M, Dimoglo A (2016) Desalin. Water Treat. 57: 11375-11385.

Blaha L, Bolchi M, Gawlik BM (2010) Water. Res. 44: 4115-4126.

Calza P, Sakkas VA, Medana C, Baiocchi C, Dimou A, Pelizzetti E, Albanis T (2006) Appl. Catal. B-Environ. 67: 197-205.

Evanson NK (2007) Diclofenac xPharm: The Comprehensive Pharmacology Reference. 1-7.

Güyera GT, Ince NH (2011) Ultrasonic Sonochemistry 18: 114-119.

Kubiňáková E, Kerekeš K, Gál M, Híveš J (2015) J. Appl. Electrochem. 45: 1035-1042.

Loos R, Carvalho R, António DC, Comero S, Locoro G, Tavazzi S, Paracchini B, Ghiani M, Lettieri T, Blaha L, Jarosova B, Voorspoels S, Servaes K, Haglund P, Fick J, Lindberg RH, Schwesig D, Gawlik BM (2013) Water. Res. 47: 6475-6487.

Loos R, Locoro G, Comero S, Contini S, Schwesig D, Werres F, Balsaa P, Gans O, Weiss S, Verlicchi P, Aukidy M, Zambello E (2012) Sci. Total Environ. 429: 123-155.

Luo Y, Guoa W, Ngo HH, Nghiemb LD, Hai FI, Zhang J, Liang S, Wang XC (2014) Sci. Total Environ. 473-474: 619-641.

Mackulak T, Birošová L, Bodík I, Grabic R, Takáčová A, Smolinská M, Hanusová A, Híveš J, Gál M (2016) Sci. Total Environ. 539: 420-426.

Manoli K, Nakhla G, Ray AK, Sharma VK (2017) Chem. Eng. J. 307: 513-517.

Manu B, Mahamood R (2012) J. Sustainable Energy \& Environment 3: 173-176.

Naddeo V, Belgiorno V, Ricco D, Kassinos D (2009) Ultrasonic Sonochemistry 16: 790-794.

Pérez-Estrada LA, Malato S, Gernjak W, Agüera A, Thurman EM, Ferrer I, Fernández-Alba AR (2005) Environ. Sci. Technol. 39: 8300-8306.

Rivera-Utrilla J, Sánchez-Polo M, Ferro-García MA, Prados-Joya G, Ocampo-Pérez R (2013) Chemosphere 93: 1268-1287.

Rizzo L, Meric S, Kassinos D, Guida M, Russo F, Belgiorno V (2009) Water. Res. 43: 979-988.

Sharma VK, Chen L, Zboril R (2016) ACS Sustainable Chem. Eng. 4: 18-34.

Todd PA, Sorkin EM (1988) Drugs 35: 244-285.

Vogna D, Marotta R, Napolitano A, Andreozzi R, Ischia M (2004) Water. Res. 38: 414-422.

Zhao X, Hou Y, Liu H, Qiang Z, Qu J (2009) Eletrochim. Acta 54: 4172-4179. 